Pacific Northwest

\title{
Lessons Learned from the Development of an Example Precision Information Environment for International Safeguards
}

\section{December 2014}

ZN Gastelum

MJ Henry

ER Burtner, IV

JR Doehle
SD Hampton

RR La Mothe

PL Nordquist

DV Zarzhitsky 


\title{
DISCLAIMER
}

This report was prepared as an account of work sponsored by an agency of the United States Government. Neither the United States Government nor any agency thereof, nor Battelle Memorial Institute, nor any of their employees, makes any warranty, express or implied, or assumes any legal liability or responsibility for the accuracy, completeness, or usefulness of any information, apparatus, product, or process disclosed, or represents that its use would not infringe privately owned rights. Reference herein to any specific commercial product, process, or service by trade name, trademark, manufacturer, or otherwise does not necessarily constitute or imply its endorsement, recommendation, or favoring by the United States Government or any agency thereof, or Battelle Memorial Institute. The views and opinions of authors expressed herein do not necessarily state or reflect those of the United States Government or any agency thereof.

\author{
PACIFIC NORTHWEST NATIONAL LABORATORY \\ operated by \\ BATTELLE \\ for the \\ UNITED STATES DEPARTMENT OF ENERGY \\ under Contract DE-AC05-76RL01830 \\ Printed in the United States of America
Available to DOE and DOE contractors from the
Office of Scientific and Technical Information,
P.O. Box 62, Oak Ridge, TN 37831-0062;
ph: (865) 576-8401
fax: $(865) 576-5728$
email: reports@adonis.osti.gov

Available to the public from the National Technical Information Service

5301 Shawnee Rd., Alexandria, VA 22312

ph: (800) 553-NTIS (6847)

email: orders $a$ ntis.gov $<$ http://www.ntis.gov/about/form.aspx $>$

Online ordering: http://www.ntis.gov

This document was printed on recycled paper.

$$
(8 / 2010)
$$




\title{
Lessons Learned from the Development of an Example Precision Information Environment for International Safeguards
}

\author{
ZN Gastelum \\ SD Hampton \\ MJ Henry \\ RR La Mothe \\ ER Burtner, IV \\ PL Nordquist \\ JR Doehle \\ DV Zarzhitsky
}

December 2014

Prepared for

the U.S. Department of Energy

under Contract DE-AC05-76RL01830

Pacific Northwest National Laboratory

Richland, Washington 99352 



\section{Summary}

The International Atomic Energy Agency (IAEA) is interested in increasing capabilities of IAEA safeguards inspectors to access information that would improve their situational awareness on the job. A mobile information platform could potentially provide access to information, analytics, and technical and logistical support to inspectors in the field, as well as providing regular updates to analysts at IAEA Headquarters in Vienna or at satellite offices. To demonstrate the potential capability of such a system, Pacific Northwest National Laboratory (PNNL) implemented a number of example capabilities within a PNNL-developed precision information environment (PIE) on a tablet computer. PNNL's safeguards proof-of-concept PIE intends to

- demonstrate novel applications of mobile information platforms to international safeguards use cases

- demonstrate proof-of-principle capability implementation

- provide "vision” for capabilities that could be implemented.

This report documents the lessons learned from this two-year development activity for the Precision Information Environment for International Safeguards (PIE-IS), describing the developed capabilities, technical challenges, and considerations for future development, so that developers working to develop a similar system for the IAEA or other safeguards agencies might benefit from our work. 



\section{Acknowledgments}

This work was sponsored by the U.S. Department of Energy's National Nuclear Security Administration Next Generation Safeguards Initiative (NGSI), under the NGSI Technology portfolio. The work was completed between October 2012 and December 2014, and leveraged the architecture of the Precision Information Environment (PIE) developed at the Pacific Northwest National Laboratory (PNNL) for the emergency response community under the U.S. Department of Homeland Security, and with support from Laboratory Directed Research and Development funding. For more information on PIE work at PNNL, see: http://www.precisioninformation.org/. 



\section{Acronyms and Abbreviations}

$\begin{array}{ll}\text { CIR } & \text { computerized inspection report } \\ \text { FAR } & \text { Field Activity Reporting } \\ \text { GPS } & \text { Global Positioning System } \\ \text { IAEA } & \text { International Atomic Energy Agency } \\ \text { LDRD } & \text { Laboratory Directed Research and Development program } \\ \text { NGSI } & \text { Next Generation Safeguards Initiative } \\ \text { OCR } & \text { optical character recognition } \\ \text { PIE } & \text { Precision Information Environment } \\ \text { PIE-IS } & \text { Precision Information Environment for International Safeguards } \\ \text { PNNL } & \text { Pacific Northwest National Laboratory }\end{array}$





\section{Contents}

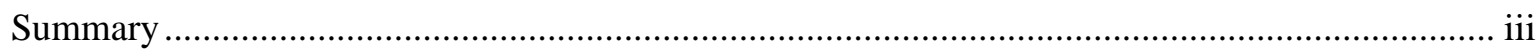

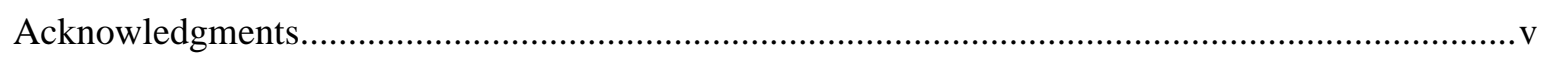

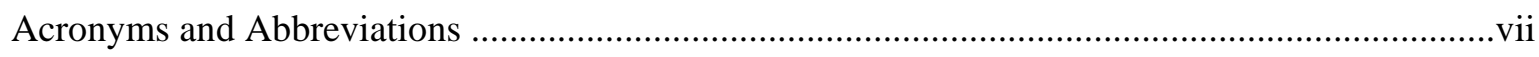

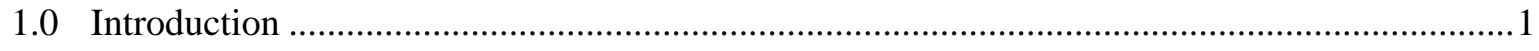

1.1 Precision Information Environment Background...........................................................

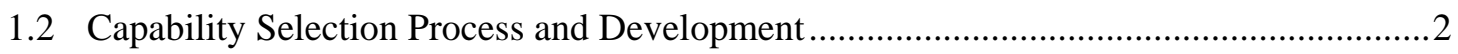

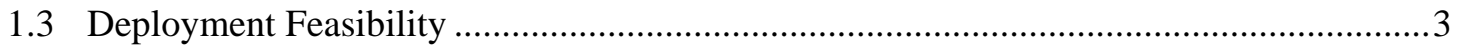

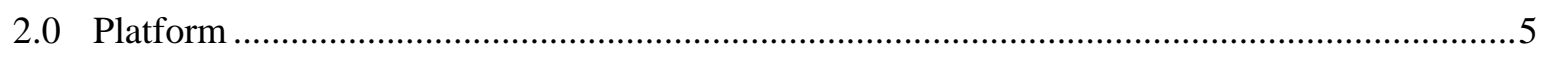

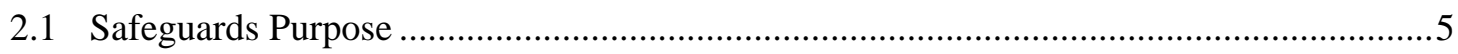

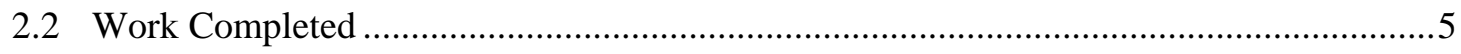

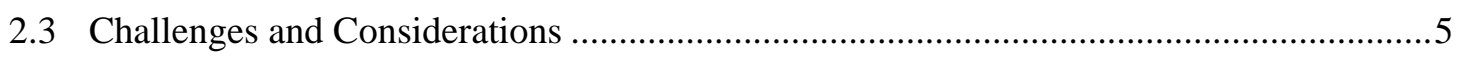

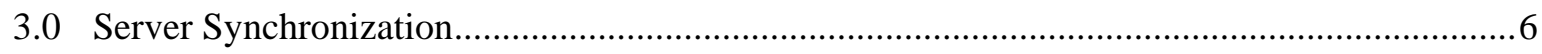

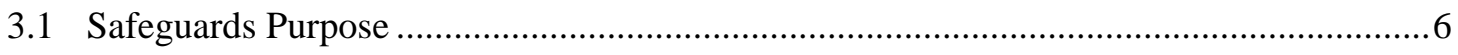

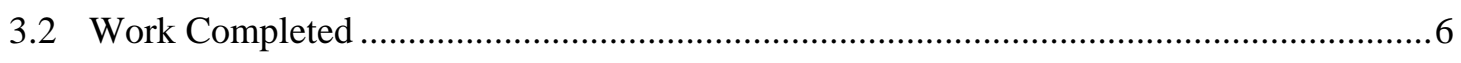

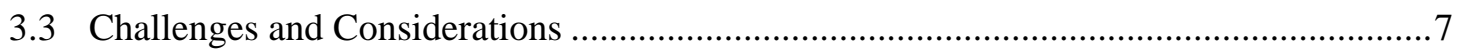

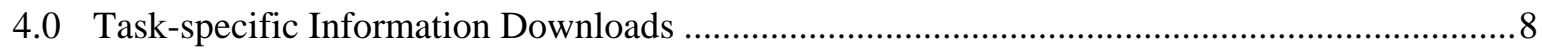

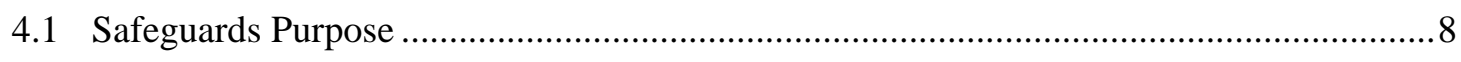

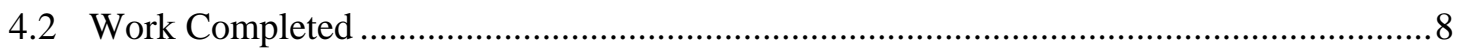

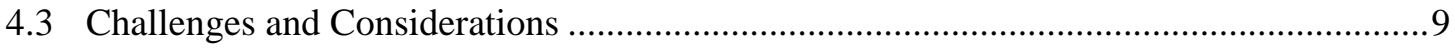

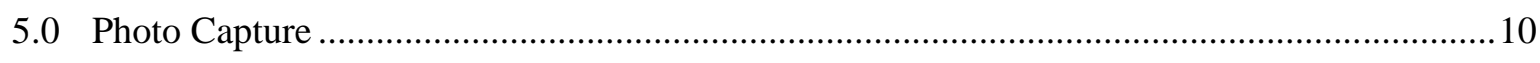

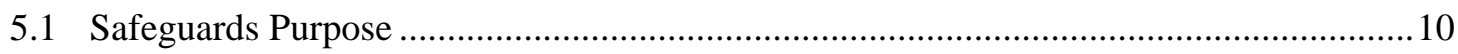

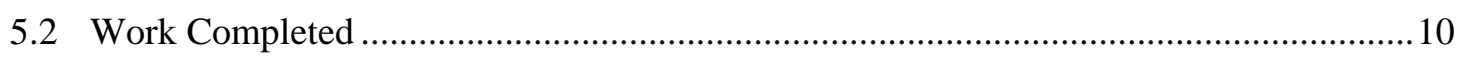

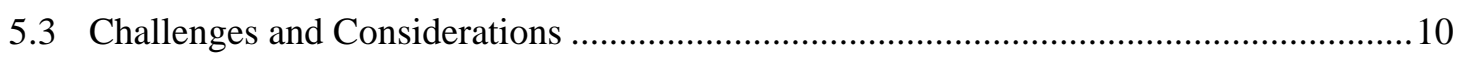

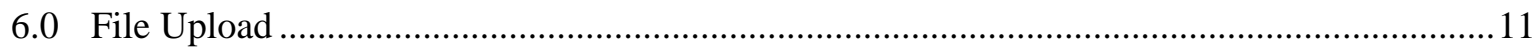

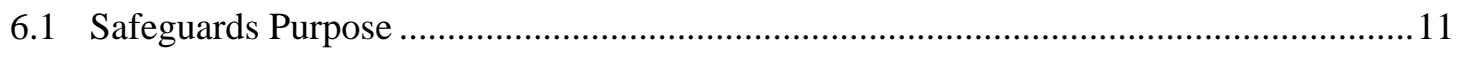

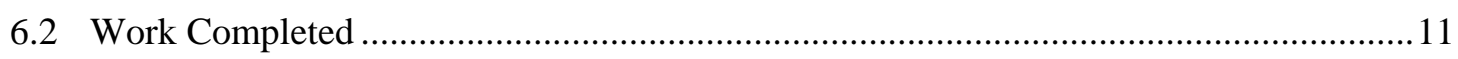

6.3 Challenges and Considerations …………....................................................................

7.0 Computerized Inspection Report Completion Support......................................................12

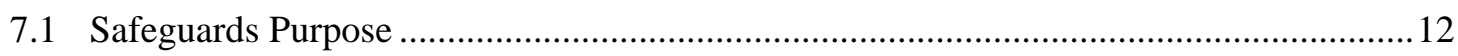

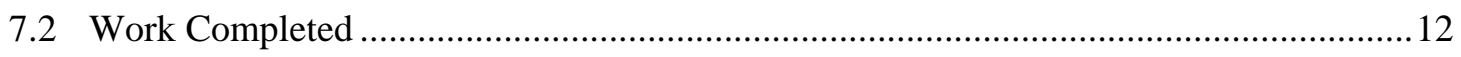

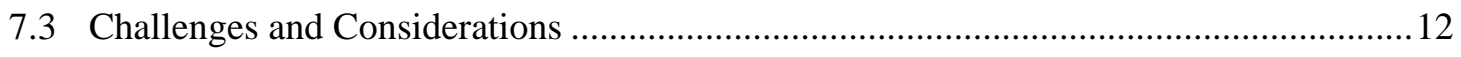

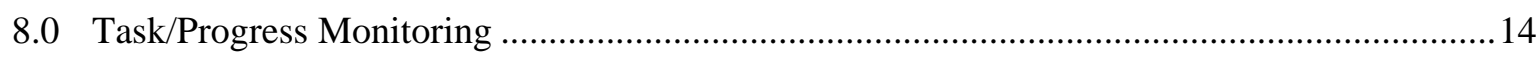

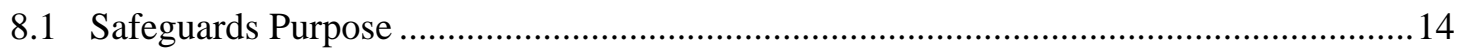

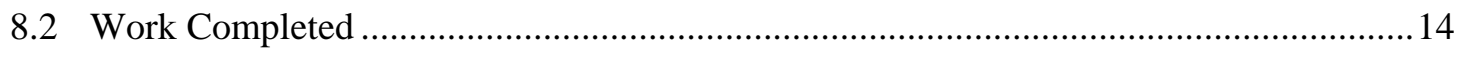

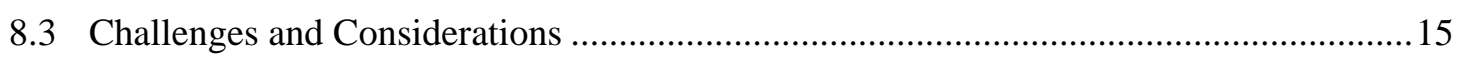

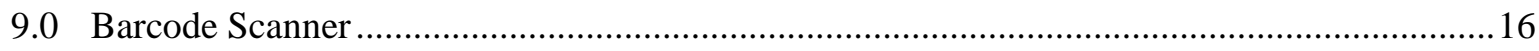




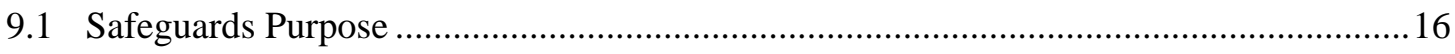

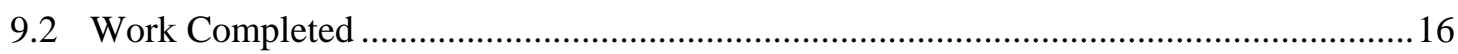

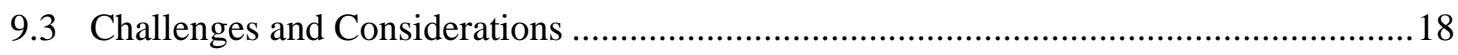

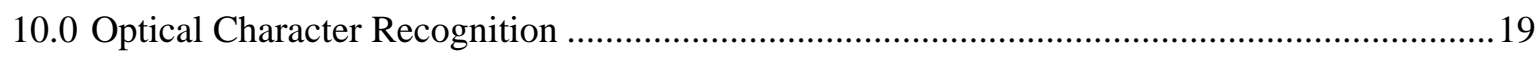

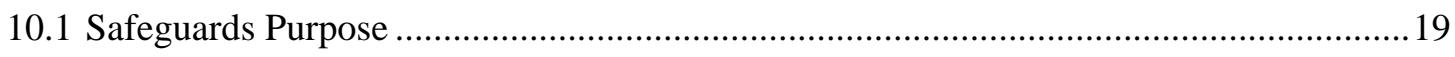

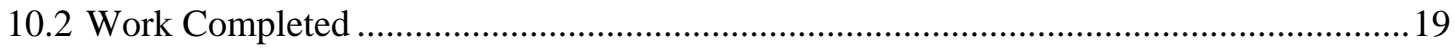

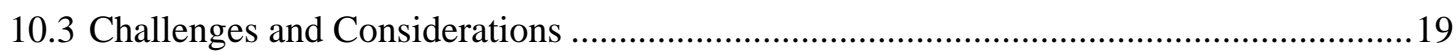

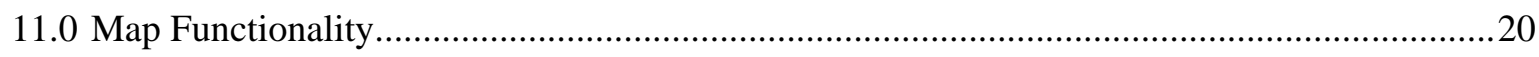

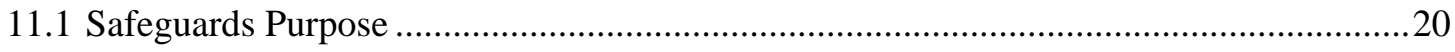

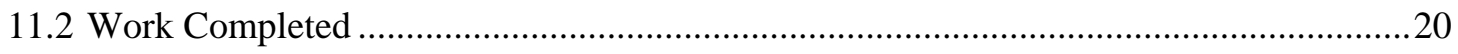

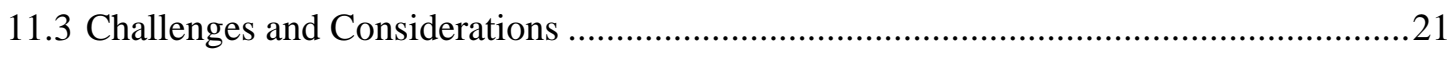

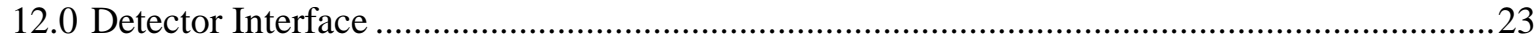

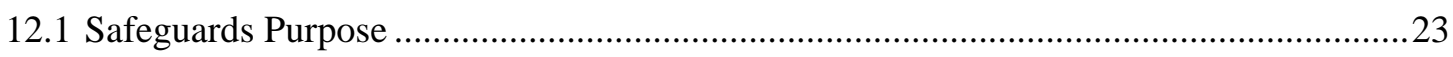

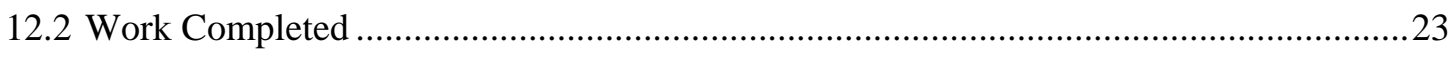

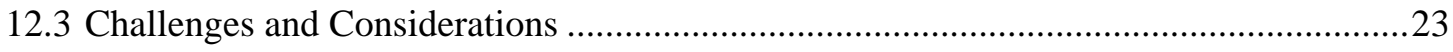

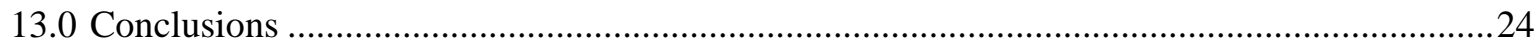

\section{Figures}

1. New, Unread Documents Appear in Red to Call the User's Attention to Timely Information ....... 7

2. Safeguards-relevant Documents, Including Modules of the Computerized Inspection Report, are Automatically Downloaded to the Tablet Depending on the Selected Safeguards Activity... 9

3. Users Can Fill Out CIR Mmodules within PIE-IS ...................................................................... 12

4. Task Monitoring Tracks the Completion of CIR Modules and Displays Overall Task Completion in the Bottom Left of the Task’s Work Environment ............................................... 15

5. The User Scans a Barcode with the Tablet's Integrated Camera .................................................. 17

6. Upon Recognition of the Barcode, Information about the Scanned Item is Retrieved from a Database. 


\subsection{Introduction}

As international safeguards evolve to integrate more State-level information, safeguards inspectors are responsible for being aware of, and acting upon, an increasing amount of information while in the field. In addition, the expansion of nuclear fuel cycle activities is expanding both within existing nuclear energy states, and to new and planned nuclear energy states. To make safeguards-relevant information more available to safeguards inspectors working in the field, and support their cognitive juggling of technical requirements, task progress, and other relevant information, Pacific Northwest National Laboratory (PNNL) developed a proof-of-concept instantiation of a precision information environment (PIE) for international safeguards.

Through the development of a proof-of-concept system for international safeguards, the project intends to

- demonstrate novel applications of mobile information platforms to international safeguards use cases

- demonstrate proof-of-principle capability implementation

- provide "vision” for capabilities that could be implemented.

In this report, we will describe the capabilities implemented under the Precision Information Environment for International Safeguards (PIE-IS) project. For each capability, we will include:

- a brief explanation of what the capability is/does

- a description of the potential international safeguards uses

- a summary of the final product developed under the project

- an outline of challenges we encountered and considerations for future development if such a system were to be deployed as an engineered, operational mobile information platform.

It should be noted that while work performed on this project was completed for International Atomic Energy (IAEA) safeguards use cases, the development itself was done as a proof-of-concept using PNNL’s data, system architecture, and hardware.

\subsection{Precision Information Environment Background}

PNNL's PIE is a secure, collaborative environment that supports remote data acquisition, scalable storage, automated processing, analysis, machine learning, and collaborative interaction from a centralized location for both local and mobile clients. The software provides an intuitive and interactive interface for displaying and analyzing data in the field and supports access via both mobile device clients (e.g., tablet computers and smart phones) and desktop clients. At the same time, data collected in the field can be shared with operations centers. PNNL's PIE was originally planned to support the emergency response community, to enable real-time communication with personnel in the field during routine and emergency events.

The impact of real-time information sharing is greatest when the in-field personnel and operations centers are connected via a high-bandwidth internet connection. However, PIE can also improve 
information sharing if the mobile user is not online: upon reconnection to the Internet, PIE can upload and download appropriate content, indicate what is new, and analyze and group data by theme in order to minimize information overload. Users can interact with PIE in a number of different modes based on their roles or the activities they are performing, including a "dashboard" mode that is used to indicate current status of activities, display outstanding tasks and to whom they are assigned, and any other information that is deemed useful for that user.

\subsection{Capability Selection Process and Development}

Throughout the PIE-IS project, and in coordination with the policy research effort described below in Section 1.3, the team received input from former IAEA safeguards inspectors as well as safeguards technology developers, information technology professionals, and other safeguards practitioners regarding capabilities that could be useful or interesting to develop for a PIE-like system. There are many capabilities that could be deployed to a mobile information platform such as PIE that could be relevant to international safeguards inspectors. Most of the capabilities were far outside the scope of the PIE-IS project, but could be of interest to others developing such a system.

For the PIE-IS project, the capabilities were for development based on schedule and budget considerations, near-term safeguards relevance, and client interest. The capabilities developed in the PIEIS project

- $\quad$ automatically synchronize data with the remote PIE-International Safeguards server

- download, display and recommend task-specific information appropriate for the type of inspection activity being conducted

- $\quad$ enable inspector to view, take, and upload photos

- enable user to photograph documents in a searchable format via optical character recognition software

- $\quad$ enable scanning of barcodes for tracking or other purposes (e.g., such as those applied to $\mathrm{UF}_{6}$ cylinders)

- facilitate inspector completion of Computerized Inspection Report via “Modules” tab

- $\quad$ support progress monitoring and management of safeguards task/activity via "Modules” tab

- $\quad$ provide the ability to open and view maps with safeguards-relevant information overlays (such as facility and site information).

In addition, the capability to communicate with, and ingest data and analysis from, radiation detection equipment from within PIE-IS was examined, but development was not completed due to a series of technical challenges.

Other proposed capabilities for such a system that could be considered on future development projects include: 
- Logistics support, providing inspectors with hotel and restaurant recommendations, transportation support (maps, service providers, etc.), and medical advice

- Translation support, including either voice- or text-translation support, or provision of key phrases

- Live communication services to IAEA Headquarters for management advice, technical support for equipment, legal consultations, or analyst input

- Voice-to-text recording of inspector observations

- Availability- and role-based tasking support for follow-up actions and inspector questions

- Geo-location-enabled capabilities including trip tracking within a site, or utilization of a gyroscope, accelerometer, or other technology to map inspector movement and tag relevant safeguards information as an inspector moves within a facility.

\subsection{Deployment Feasibility}

The technical challenges associated with developing a mobile information platform for international safeguards are expected to be commensurate with any such development activity. Compounding the technical issues are a series of deployment challenges that must be understood by the end-use organization as well as the development team. In FY 2014, the Next Generation Safeguards Initiative (NGSI) funded a complementary policy project to the PIE-IS work to identify the potential deployment barriers for an IAEA safeguards inspector using a tablet in the field. Through extensive literature and expert elicitation, the project identified 12 barriers to the implementation of a mobile information platform for safeguards:

- Safety, including facility safety and personnel/inspector safety

- Security, including operation and information security

- Infrastructure, related to wireless connectivity and Internet, power supply, and data storage

- Information architecture

- Sustainability, both of hardware and software
- Regulatory compliance and facility policy

- $\quad$ Staffing

- Software transition and deployment

- Transparency

- Usability

- Sociocultural

- Cost. 
For each potential barrier, the project developed a series of recommendations on how those challenges might be mitigated. ${ }^{1}$ Those mitigation strategies should be considered in tandem to technical requirements for an international safeguards mobile information platform. Though the final report from that project concluded that many of the challenges facing the deployment of tablets to field are similar to those faced with the current use of inspector laptops, some unique (or especially emphasized) challenges led to the following recommendations for an IAEA mobile information platform development project:

- Consider flexibility and ease of deployment

- Plan a phased roll-out

- Segregate personal and professional accounts

- Leverage existing projects and policies

- Consider the spectrum of deployment scenarios, costs, and benefits.

Follow-on research is being conducted in FY 2015 to develop several tablet deployment scenarios across technology-integration levels:

- one basic deployment scenario focusing on digitization and automation of paperwork

- one moderately advanced deployment scenario including some advanced analytics and collaboration capabilities

- one highly advanced deployment meant to illustrate the full potential of using collaborative information platforms to support international safeguards inspections.

The project team will conduct a quantitative impact assessment to analyze how each of the presented scenarios would affect the time, cost, and effectiveness of international safeguards inspections compared to current practices. By understanding the potential costs and benefits of various deployment scenarios, the IAEA or other safeguards bodies will be better informed as they research and invest in tablet-based information systems.

\footnotetext{
${ }^{1}$ Gastelum ZN, ET Gitau, JR Doehle, and CM Toomey. 2014. Feasibility Study of Implementing a Mobile Collaborative Information Platform for International Safeguards Inspections. PNNL-23716, Pacific Northwest National Laboratory, Richland, Washington.
} 


\subsection{Platform}

The platform refers to the device on which software is expected to function. It can range from a desktop or laptop computer to a mobile device such as a tablet or smart phone. In addition to the class of physical hardware that is selected, the operating system of a selected device must be selected as well.

\subsection{Safeguards Purpose}

Safeguards inspectors are required to carry and account for equipment in the field. In an attempt to reduce pack-weight of inspectors, mobile devices were targeted for development on this project. A tablet was chosen as the preferred mobile device (rather than a smart phone) because of its larger screen size, which enables the kinds of tasks an inspector would be expected to perform—reading documents, filling out paperwork, logging seals/samples, or interacting with radiation detection equipment.

\subsection{Work Completed}

In order to leverage the PIE framework developed by PNNL under the U.S. Department of Homeland Security (DHS) for the domestic emergency response community and extended through investments made by PNNL's Laboratory Directed Research and Development (LDRD) program, the project team developed PIE-IS for Android ${ }^{\mathrm{TM}}$.

The hardware used for development and testing of the code included two Samsung Android tablets, and one Asus Nexus ${ }^{\mathrm{TM}}$ tablet. The Samsung tablets were selected based on cost competitiveness, while the Asus was selected for its ability to connect to high-definition multimedia interface (HDMI) so that we could project the screen for demonstrations.

\subsection{Challenges and Considerations}

The IAEA or other safeguards bodies that chose to develop a tablet-based information platform will have their choice of three major operating systems: Android, iOS (Apple), and Windows ${ }^{\circledR}$. Each platform has its own unique challenges and advantages. While the project opted for Android for this proof-ofconcept because of the existing server architecture under PIE, many existing IAEA software programs and radiation detectors operate in a native Windows environment. Conversely, some new equipment such as the Canberra seals reader is being developed on an iPhone ${ }^{\circledR}$ (iOS), and the IAEA is issuing iPhones to safeguards inspectors to take in the field, giving iOS an advantage in system familiarity and some interaction capability.

Any information environment project for safeguards will have to take into account the end-user agency's technical system requirements, existing hardware and software compatibility, user requirements, information security, and other technical specifications. 


\subsection{Server Synchronization}

Server synchronization (or "sync") refers to the data harmonization between a central server and mobile information systems, so that additions, edits, and other changes occurring within an information system either at headquarters or in the field are reflected for all users of the system.

The ability to operate online (connected to the Internet) or off-line (disconnected from the Internet) requires that server synchronizations be coordinated such that online users can complete their work allowing for regular updates, while off-line workers can cache their work locally to be synched upon the next connection to the Internet. Online and off-line functionality may be identical in both operating modalities, may have minor differences in terms of capabilities such as data transmission, or may have significant differences in operational capabilities when connected or disconnected from the Internet.

\subsection{Safeguards Purpose}

Safeguards inspectors working in the field need access to inspection-relevant data such as State declarations, sampling results, previous inspection reports, and open source analysis. Yet, facility infrastructure as well as operator regulations make it unlikely that reliable wireless Internet connections are available. In order to ensure that inspectors are still able to access, edit, and add to information collections, safeguards inspectors will require the ability to work online and off-line.

\subsection{Work Completed}

PIE-IS has two operational modalities, of which there is limited difference apparent to the user.

In the online mode, the user has access to information tagged as required for his task. The user can edit documents such as required activity documentation, and can add new information to his activity that will be immediately available to other users who have the appropriate access for that activity. The user also receives new information from the server with each sync (spurred by certain user action such as adding a file, refreshing a list, or manually by selecting the "sync" option).

In the off-line mode, the user has access to the same information required for his task as above. He can edit documents in the activity and can add new files, both of which will become available to other users upon the next sync to the server (when the user is once again connected to the Internet).

PIE-IS has a basic syncing functionality in which all files within the application are refreshed with each sync. New documents that have been added to the server since the user's last sync are denoted in red (see Figure 1). 


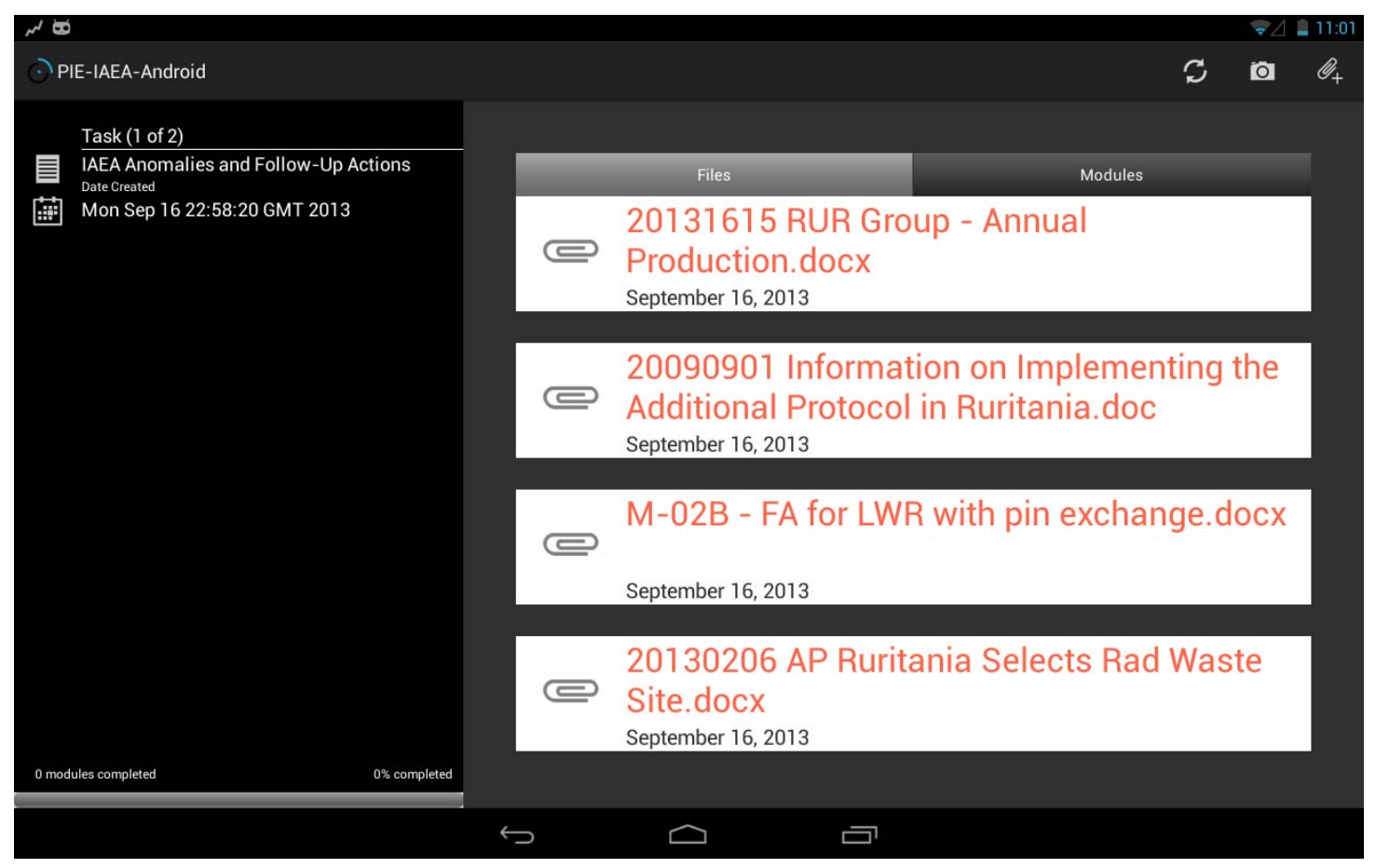

Figure 1. New, Unread Documents Appear in Red to Call the User's Attention to Timely Information

\subsection{Challenges and Considerations}

The pervasiveness of "syncing" with the server will need to be considered based on the users' needs, whether it should be constantly updated, updated only on command of the user, or also synced via certain user actions such as adding or modifying documents, opening a task, etc. In addition, file size and the frequency and amounts of modifications to information within the system will account for sync considerations. There are existing cloud-based commercial "smart sync" programs that can help with a more efficient sync function.

In some nuclear facilities under international safeguards, certain data will not be allowed to be transmitted outside of the facility, or will not be allowed to be transmitted via wireless Internet connections. In other instances, State-provided data available at IAEA Headquarters may be too sensitive to take into the field. Any implementation of server synchronization will require an evaluation for information security, and may require the option to exclude some data from syncing.

In an operational deployment, multiple users (such as inspectors working together on an inspection) would have read/write access to files within an inspection task or activity. Future development activities would need to consider the interaction of multiple users on a single document at the same time. 


\subsection{Task-specific Information Downloads}

Task-specific information downloads refer to the automated identification and downloading of safeguards-relevant information from IAEA information systems to a PIE-IS instantiation on a tablet, within a safeguards activity to which that information is relevant.

\subsection{Safeguards Purpose}

While safeguards inspectors are working in the field, they have limited access to information from IAEA Headquarters. In some cases, inspectors may be away from Headquarters for several weeks, and may miss the recent sampling results, statistical analyses, open source and geospatial reports, or even State reporting. To increase situational awareness for inspectors in the field, updates to information relevant to their current safeguards activities could be transmitted to them via a mobile information system.

In addition, safeguards inspectors are collecting data and making observations that are relevant to analysts and managers working at IAEA Headquarters. Timely access to information collected in the field could increase analysts' ability to respond to inspector information requests, as well as the ability of analysts, technicians, managers, and other staff to provide more immediate feedback that could affect the work that inspectors are conducting.

\subsection{Work Completed}

In PIE-IS, PNNL developed a rule-based information download functionality, in which documents saved in specific folders were associated with different countries and inspection activities based on rules created for the system by an administrator. For example, a Design Information Verification for a nuclear facility in the fictitious state of Ruritania would instigate the download of satellite imagery of that facility. Similarly, the creation of an Interim Inventory Verification activity for Ruritania would result in the download of the state's most recent inventory change reporting for that facility (see Figure 2). 


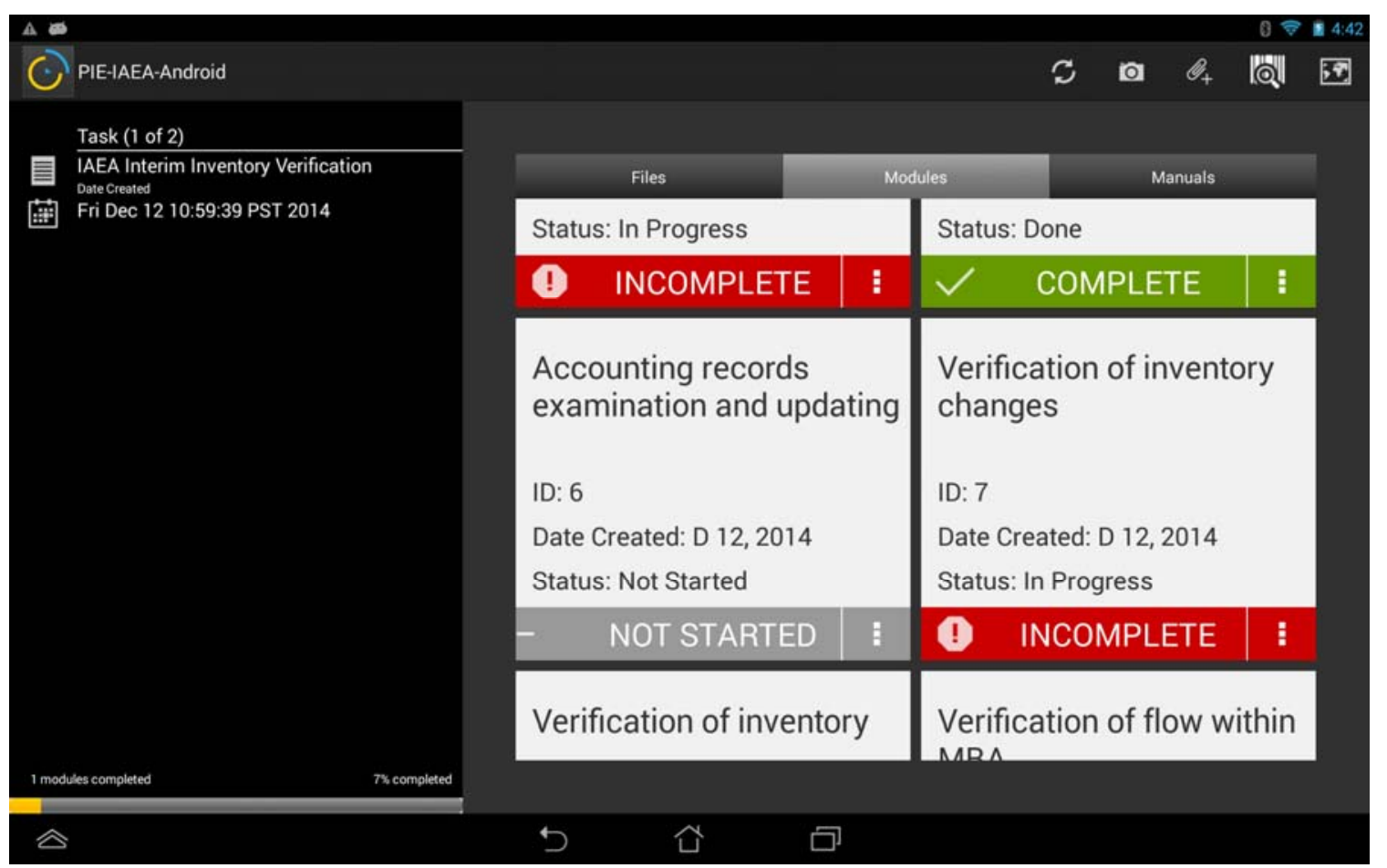

Figure 2. Safeguards-relevant Documents, Including Modules of the Computerized Inspection Report, are Automatically Downloaded to the Tablet Depending on the Selected Safeguards Activity

\subsection{Challenges and Considerations}

Though the rule-based file selection is effective on a small scale, a sophisticated recommendation engine might be considered for an engineered system, such as a system that considers metadata or keywords associated with files, or an advanced engine that can learn from, and respond to, user interactions (for example, Amazon.com-type recommendations: "Other users interested in Ruritania uranium enrichment looked at these documents.”). 


\subsection{Photo Capture}

Photo capture refers to the ability to call a device's integrated camera to take a photo within the information platform.

\subsection{Safeguards Purpose}

IAEA inspectors currently use cameras during Design Information Verification inspections, as well as in Complementary Access. Integrating a photo capture capability into a safeguards information system would allow inspectors to seamlessly take photos and upload them to their current safeguards project, and make immediate notations such as the location of the photo, the item of interest, or other important documentation that is not possible using stand-alone camera technologies.

\subsection{Work Completed}

For PIE-IS, the team used the tablet's integrated camera to allow users to take a photo from within a safeguards task, which was automatically uploaded to the file list for that task.

\subsection{Challenges and Considerations}

Considerations for photo capture capabilities are hardware quality (of the integrated camera and lens), which is driven by the selection of a mobile platform. Lighting within a nuclear facility may also drive camera or lens selection. 


\subsection{File Upload}

File upload refers to the ability to incorporate files, such as photos, documents, and other records saved to a mobile device into the information environment.

\subsection{Safeguards Purpose}

Safeguards inspectors using a tablet to support their inspections may encounter situations in which they would like to add relevant files to their task within an information environment directly from the tablet (rather than uploading directly to the information environment upon document saving). Examples might include access to new documentation provided by a facility operator; incorporation of a document that the inspector downloaded from the Internet or email; or a photo, video, or audio file recorded outside of the information environment on the mobile device that is relevant for the safeguards task.

\subsection{Work Completed}

For PIE-IS, we implemented the ability for a user to upload documents from the tablet into PIE tasks (keeping the name of the original file), including photos, MS Office documents (Word, Excel ${ }^{\circledR}$ ), and PDFs, into a standard document repository.

\subsection{Challenges and Considerations}

Future development in file upload could include additional types of files such as video and audio files. In addition, future work in this area might include the option to upload files to an engine to index, search, and analyze them in real-time on the device or the server for sharing with Headquarters. 


\subsection{Computerized Inspection Report Completion Support}

The IAEA requires that inspectors complete documentation of their safeguards inspection activities in a computerized inspection report (CIR). The CIR contains modules that are completed based on the type of safeguards inspection being conducted. Currently, the CIR is available to fill out via paper form, or with the support of a form completion wizard on a desktop or laptop computer.

\subsection{Safeguards Purpose}

For any given safeguards inspection, the lead inspector is responsible for the completion of the CIR. Having in-field support for CIR completion on a tablet could enable inspectors to fill out the CIR as they complete their work, delegate portions of the CIR that can be completed simultaneously by multiple inspectors working together in the field, and facilitate upload to IAEA archives at Headquarters.

\subsection{Work Completed}

The PIE-IS team input the CIR modules into an Excel-like spreadsheet for user form entry. Each module can be accessed separately for easier readability on a mobile device. See Figure 3 for an example CIR module.

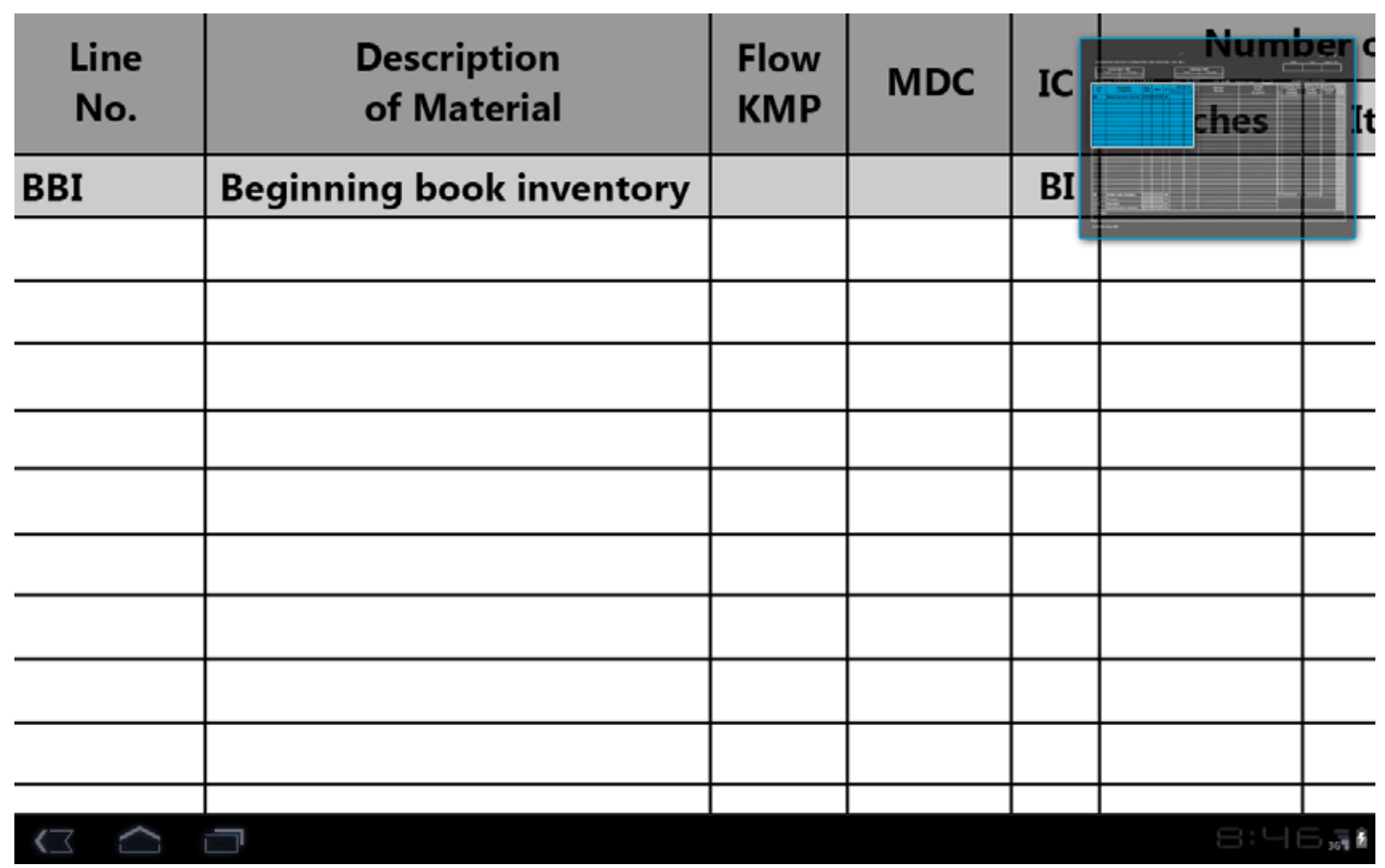

Figure 3. Users Can Fill Out CIR Modules within PIE-IS

\subsection{Challenges and Considerations}

The IAEA is developing mobile support for the CIR under the Field Activity Reporting (FAR) project, targeting tablet deployment of the CIR. 
The current instantiation of the CIR could be made into a more familiar format. Future work should revisit how modules are viewed and completed from a usability standpoint, with additional capability to flag items for follow-up, tag other users for notification, push data from the CIR into an analytics engine, and auto-feed data from a barcode reader, radiation detector, operator declaration, or other input directly into the CIR. 


\subsection{Task/Progress Monitoring}

Task and progress monitoring refers to functionality in which a user is updated on the completeness of their assignments, and directed to those tasks or activities that require their completion.

\subsection{Safeguards Purpose}

When a safeguards inspector conducts an inspection in a nuclear facility, he or she is responsible for completing a large number and types of tasks, depending on the inspection type. These activities could include examination and reconciliation of an operator's records, calibration of operator measurement equipment, verification and replacement of seals, verification through measurement of randomly selected items, review of surveillance information, and determination of mass balance of nuclear materials within a specific area of the facility. For each task, the inspector must record his or her activities in the CIR.

\subsection{Work Completed}

For PIE-IS, we developed a user-driven progress monitoring mechanism, in which the user updates the status of each CIR module as he or she performs work, from "not started" to "incomplete" to "complete." As the status of each module is updated, an overall progress monitoring function evaluates overall completion of all modules for a particular inspection type. The CIR modules in Figure 2 show progress monitoring ("Not Started," "Incomplete," and "Complete”) at the bottom of the selected modules, while Figure 4 shows the change in overall task monitoring in the bottom left corner as an inspector completes more CIR modules. 


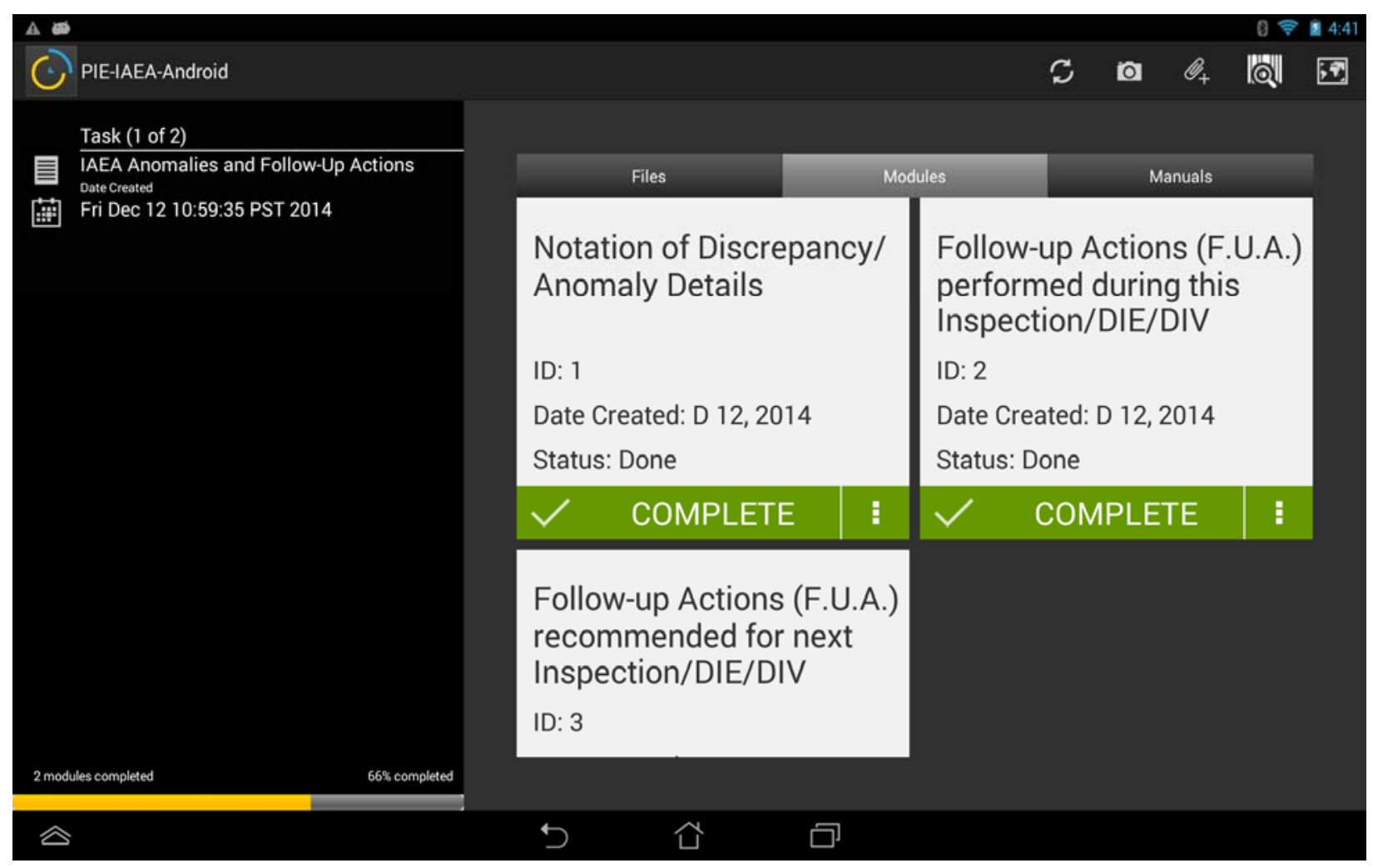

Figure 4. Task Monitoring Tracks the Completion of CIR Modules and Displays Overall Task Completion in the Bottom Left of the Task's Work Environment

\subsection{Challenges and Considerations}

For future development of task or progress monitoring, additional considerations should be made for how to update task status with multiple users updating tasks simultaneously, and dynamic updates that are based on user interaction or completion of modules, rather than manual user input. Consideration might also be made for scenarios in which not all applicable modules will be used for a safeguards inspection, so that full completion of all modules is not required for an activity to be considered complete (for example, being able to mark a module "not applicable” or “not to be completed”). 


\subsection{Barcode Scanner}

A barcode scanner refers to the ability of a tablet to use its integrated camera to identify and read barcodes and to access corresponding information associated with those codes.

\subsection{Safeguards Purpose}

Safeguards inspectors are required to catalog and keep track of various items through their inspection activities, including samples, measurement equipment, seals removed or applied, and facility containers such as $\mathrm{UF}_{6}$ cylinders. A barcode reader with connections within an information environment could allow inspectors to

- create lists of items that have barcodes for verification purposes (list of cylinders verified, lists of seals applied/removed)

- improve sample tracking between the field and Headquarters (scan the barcode when the sample is taken, scan again when received at the lab, and scan when processed, etc.)

- access additional information about equipment that has a barcode, such as technical specifications, calibration history, or user manuals associated with that equipment.

\subsection{Work Completed}

For PIE-IS, we used the integrated camera and an open source Android barcode scanner library to read barcodes and retrieve associated information from a database. For this project, we developed five barcodes as proxies for barcoded equipment, and fabricated associated data for those pieces of equipment related to recent calibration, maintenance, and user manuals. See Figure 5 and Figure 6 for a barcode scanner workflow. 


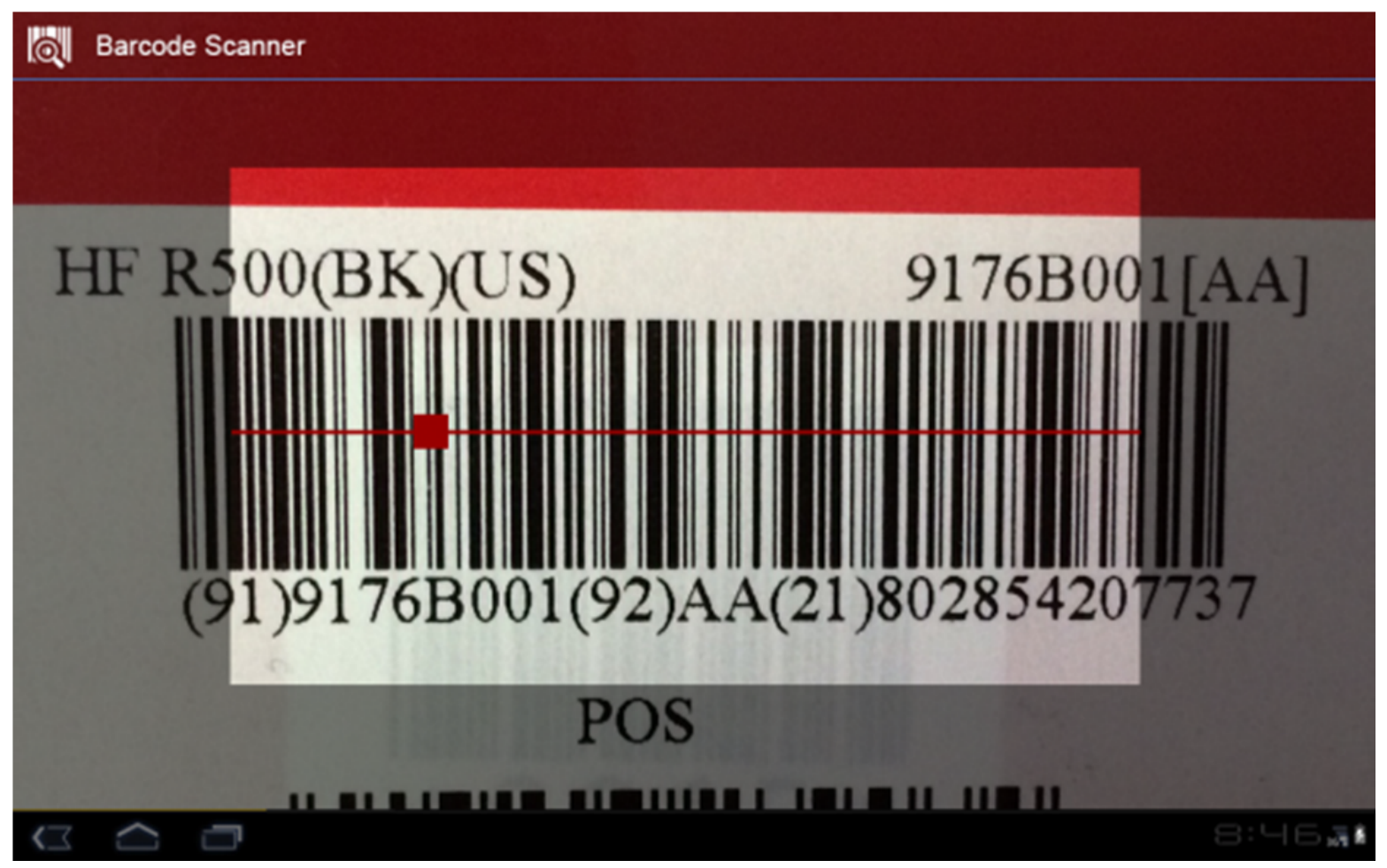

Figure 5. The User Scans a Barcode with the Tablet’s Integrated Camera

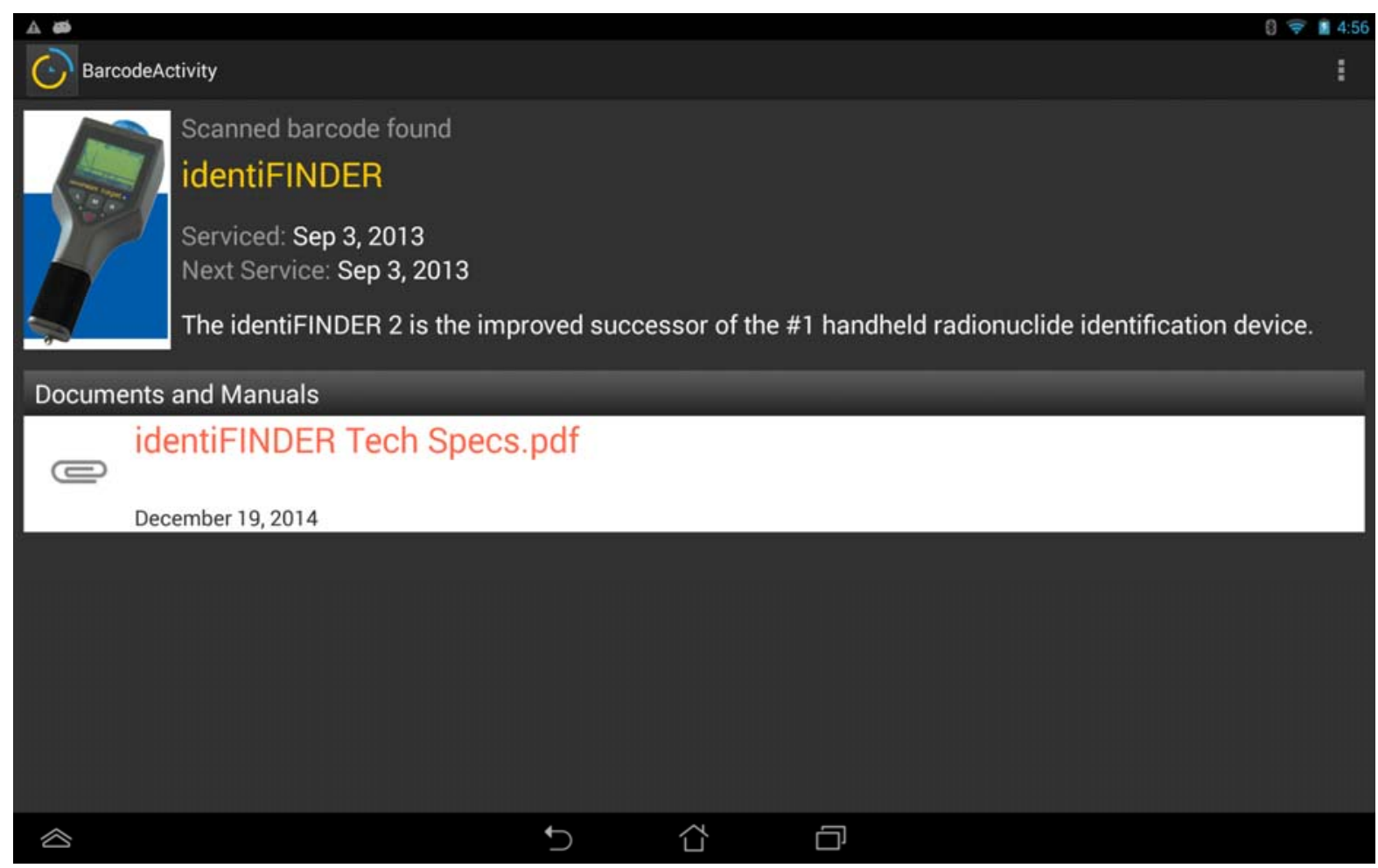

Figure 6. Upon Recognition of the Barcode, Information about the Scanned Item is Retrieved from a Database. In this case, the barcode was on an HM5 radiation detector, and scanning the barcode retrieves information about the equipment's calibration and maintenance, and a link to the user manual. 


\subsection{Challenges and Considerations}

Camera quality can pose an issue for the barcode scanner, impacting the size and resolution of barcode needed for accurate recognition. Barcode quality was another important issue. Poor quality barcodes (from low-resolution images, barcodes that were too small, or barcodes that have been worn or weathered) resulted in an inability to read the code. This could pose a serious problem for barcodes placed under the stress of an operational nuclear facility, therefore how the barcode reader will be deployed should be considered. For example, for tracking of samples prepared by IAEA inspectors and carried back to Vienna, barcodes could be expected to be of much higher quality that those attached to $\mathrm{UF}_{6}$ cylinders being put through international shipping, autoclaves, and other processing. 


\subsection{Optical Character Recognition}

Optical character recognition (OCR) is a capability that can ingest an image of a typed document (photograph, scanned document, PDF, etc.) and convert the document into searchable text.

\subsection{Safeguards Purpose}

A safeguards inspector working in the field may encounter situations in which an operator presents new or modified data on-site that the inspector needs to include in their records, for example updated inventory change reports or shipping and receiving information. Using OCR, an inspector could photograph the document with the camera on a tablet and save it as searchable text within the PIE-IS data repository.

\subsection{Work Completed}

For PIE-IS, we included an open source OCR library using the integrated tablet camera.

\subsection{Challenges and Considerations}

Though the implementation of the OCR software was straightforward, the quality of the OCR varied greatly based on hardware (camera quality), characteristics of the document to be converted to searchable text by OCR (size of text, inclusion of special characters, graphics, formatting) and environment (lighting, angle of view, and shakiness).

The team conducted two weeks of testing to determine the optimal camera, photograph angle, lighting, and document characteristics to yield a good result. These initial tests indicated that most documents of standard letter or A4 size with point 10 and above font can be processed in under a minute on the hardware tested. Minor adjustments to default memory allocation parameters allowed the application to work on full-resolution images, increasing the text extraction accuracy by $50 \%$ with images taken in low light or at an angle. Additional image pre-processing OCR algorithm tuning and a highresolution camera (5 MP or better was preferred) could be considered for future work, in order to make the best possible result in an operational environment. 


\subsection{Map Functionality}

Map functionality refers to the ability to view, modify, and access information via a map view. Map functionality is frequently discussed alongside Global Positioning System (GPS) capability that has the ability to geo-locate a device (tablet, etc.), track a device's path, and estimate measures such as distance, speed, and altitude.

\subsection{Safeguards Purpose}

There are several example situations in which maps or other geospatial awareness capabilities could support international safeguards activities.

From the logistical standpoint, inspectors are responsible for navigating within a country to and from the airport, hotel, and nuclear site. GPS functionality could assist inspectors in locating the sites they need to work in, and store recommended locations (hotels, restaurants, medical facilities) from previous visits. Once on-site, inspectors are accompanied to (and in) facilities, but a geospatial tracker could support inspectors in determining 1) if they are taking the same route through a site that was taken previously, 2) if they are navigating through a facility in a similar way as previous visits, and 3) if they are being taken to the facility that they requested. The third point is particularly important for complementary access requests, as the locations may not be familiar to the inspectors. This type of situational awareness can provide inspectors with additional information about areas that are potentially being avoided, or that may be useful for a broader State understanding.

Furthermore, a GPS-enabled map function with sufficient resolution could support inspectors completing Design Information Verification, by allowing them to pin specific locations within a site or facility to the map.

Other suggestions for GPS capability, though less likely given current technical limitations and operator restrictions, could involve a facility-based application that could identify key measurement points and previous sampling locations within a facility.

\subsection{Work Completed}

The incorporation of map or geospatial capability was not part of the funded scope for PIE-IS. However, a research associate who was made available to the team implemented a basic map viewer with an overlay of international nuclear facility locations at no cost to the project.

An open-source Android-compatible map function was implemented within PIE-IS, with an overlay of international nuclear facility locations. The nuclear facilities were color-coded by type, and available for viewing from the main activity menu, or from within a task. Upon selecting a nuclear facility icon, the user can see the name and capacity of the facility. 


\subsection{Challenges and Considerations}

For a simple map viewer, additional development would be needed to better differentiate nuclear or non-nuclear facility types, the provision of additional information within the pop-up windows (such as a photo, operational status, etc.), and task-based map zooming that would allow the user to quickly access the facility being inspected from within a PIE-IS activity (either based on activity location metadata, or GPS location identification).

The current deployed capability does not incorporate GPS. Any GPS-related capability such as navigation support and path tracking would require additional work. Because of potential sensitivities of using GPS within a nuclear facility, any development in that area could potentially require the ability to easily activate and inactivate GPS in a manner transparent to facility operators. 



\subsection{Detector Interface}

Detector interface refers to the ability of an information system to directly interact with a piece of radiation detection equipment. This could include remote operation of the equipment, live ingest of data from the detector, and real-time analysis of incoming information. It could include either wireless interface with equipment via Bluetooth, WiFi, or cellular connection, or connection via a micro-USB (universal serial bus) or other cord.

\subsection{Safeguards Purpose}

International safeguards inspectors use various pieces of radiation detection equipment to detect, identify, and quantify radioactive materials within nuclear facilities. A direct interface with that detection equipment from a mobile information platform could facilitate the ingestion and recording of measurements from such equipment.

\subsection{Work Completed}

For this project, we investigated the feasibility of interacting with an identiFINDER 2 via PIE-IS running on an Android tablet. The research specifically aimed at determining feasibility to read data (spectra, country, etc.) from the identiFINDER 2 for display on the tablet, and to control the device (start spectra collection, set configuration parameters) from the tablet. The identiFINDER 2 has two communication interfaces_-Bluetooth and USB — both of which were investigated in this project.

\subsection{Challenges and Considerations}

Ultimately, with the funds allocated for this investigation (approximately 50 staff hours), the PIE-IS team was unable to achieve direct interface between PIE-IS and the indentiFINDER2. This primarily resulted because of the incompatibility of the communication protocols between the identiFINDER and an Android tablet, but also because of the disparity between the two operating systems - the indentiFINDER2 runs embedded Windows, which presented an incompatibility with the Linux-based Android operating system on the tablet. The documentation received from the manufacturer was incomplete, with partial information and broken links to additional information. Additional documentation from the manufacturer could help determine what may be achievable. Other projects at PNNL have had success deploying Microsoft Windows "Professional" tablets with radiation detection equipment, as the operating system is identical to that which the sensors would interact with on a laptop or desktop computer. While non-Android tablets are outside the scope of the PIE-IS project, both Windows and iOS platforms should be considered as other potential options for tablet-detector interface. 


\subsection{Conclusions}

In this project, we explored the implementation of a variety of open source capabilities into the PIEIS framework to support an international safeguards use case. The work was meant to serve as a demonstration that such capabilities could be incorporated into a system for potential use by the IAEA, rather than to develop an engineered and ready-to-deploy system. The capabilities we implemented were not intended to be exhaustive of what might be used for an international safeguards mobile information platform. In the process of developing and implementing these capabilities, the PIE-IS team documented various challenges, lessons learned, and potential areas for future development, which are captured in this report. It is hoped that other tablet projects developed for international safeguards can use the lessons learned from the PIE-IS project to inform their development, and avoid issues or challenges that we encountered.

In addition to the technical challenges associated with developing a mobile information platform for international safeguards, there are deployment issues that must also be considered. As such, the authors encourage safeguards agencies, developers, and others working on mobile information platforms for international safeguards to also consider the lessons from the 2014 NGSI study on the feasibility of deploying mobile information platforms for international safeguards. ${ }^{1}$

\footnotetext{
${ }^{1}$ Gastelum ZN, ET Gitau, JR Doehle, and CM Toomey. 2014. Feasibility Study of Implementing a Mobile Collaborative Information Platform for International Safeguards Inspections. PNNL-23716, Pacific Northwest National Laboratory, Richland, Washington.
} 



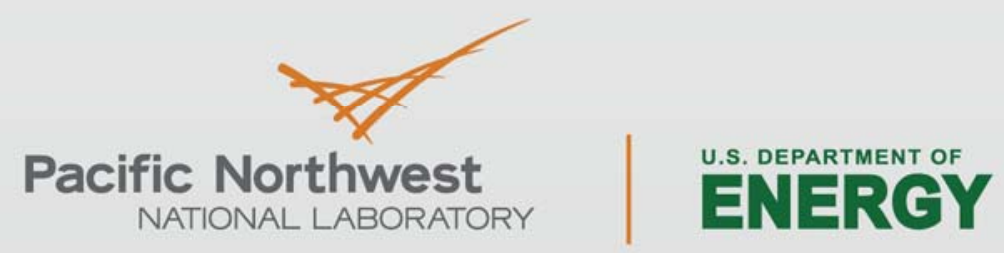

Proudly Operated by Battelle Since 1965

902 Battelle Boulevard

P.O. Box 999

Richland, WA 99352

1-888-375-PNNL (7665)

www.pnnl.gov 